lakes and Teocalli Mountain, Central Colorado, with remarks on the glacial phenomena of that region.-C. E. Bessey, sketch of. the progress of botany in the United States in the year 1879.C. S. Minot, sketch of comparative embryology, No. 5 ; on the general principle of development. - The Editor's Table.-Permanent exhibition of Philadelphia.-Recent literature.-A new edition of Packard's "Zoology" is announced.-General Notes. Scientific news. Proceedings of scientific societies.

Revue des Sciences Naturelles, December, 1880, contains: Herborisations of Strobelberger about Montpellier in I620, translated, with notes, by M. Kieffer (a complete exposé of the extraordinary plagiarism of Strobelberger, who copied his work on the plants of Montpellier almost verbatim from the work of Lobel) - M. Doumet-Adanson, on an immense Calamary taken near Cette, January, I880 (Ommastrephes sagittata). This specimen was nearly six feet in length, from the end of the body to the tops of the arms.-M. S. Jourdain, on the late development of scales in the eels.-E. Dubrueil, catalogue of testaceous mollusca collected from the French shores of the Mediterranean. -M. Reitsch, an analysis of Falkenberg's researches on the fecondation and alternation of generation in Cutleria.-F. Fontannes, on the stratigraphical position of the Pliocene group of Saint Aries, in the Western Bas-Dauphiné, and particularly in the environs of Hauterives (Drôme).-Scientific Reports and Bulletin.

Gegenbaur's morphologisches Jahrbuch, Band 6, Heft 4.-Dr. M. v. Davidoff, contribution to the comparative anatomy of the posterior limb masses in fishes, 2nd part (Plates 2I, 23); Dr. W. Pfitzner, on the epidermis in the amphibia (Plates 24, 25); J. E. V. Boas, on the conus arteriosus in Butirinus albula and in other Teleostei (Plate 26); Dr. H. Rabl-Rückhard, on the mutual relations between the chorda, hypophysis and the middle ridge of the skull in the embryos of the sharks', \&c., brains (with Plates 27, 28) ; Carl Rabl, on the "pedicle of invagination," \&c., in Planorbis (Plate 29) ; Prof. R. Wiedersheim, on the duplication of the os centrale in the carpus and tarsus of Axolotl (Plate 30); Prof. C. Gegenbaur, critical remarks on polydactylism as atavism; short notices; W. Leche, on the morpology of the pelvic region in the Insectivora.

Archives des Sciences Physiques et Naturelles, December 15, 1880. - Tertiary man in Portugal, by M. Choffat,-Monograph of the ancient glaciers and the erratic formation of the middle part of the Rhone valley, by MM. Falsan and Chantre.-Organic dust of the atmosphere, by Dr. Yung.-On the question of lowering of the high waters of the Lake of Constance, by M. Achard.

\section{SOCIETIES AND ACADEMIES LONDON}

Royal Society, January 6.-Observations on the Structure of the Immature Ovarian Ovum in the Bird and Rabbit, and on the Mode of Formation of the Discus Proligerus in the Rabbit and of the "Egg-Tubes" in the Dog. By E. A. Schäfer, F.R.S.

The first part of the paper is devoted to a minute description of the young ovarian ova of the bird as seen in sections of the ovary of a laying hen. The germinal spot is described as composed of two distinct substances, namely, a homogeneous matrix staining but slightly with logwood and a number of coarse granules imbedded in it, which become darkly stained. The germinal spot may often be seen to be connected with the wall of the germinal vesicle by a network of fine filaments (intranuclear network). Appearances are also deseribed which indicate that two germinal vesicles may be originally present in one ovum (? formed by the fusion of two primitive ova), and that one of the two may afterwards disappear.

A network of filaments is also described as existing in the yolk, which in some ova shows peculiar condensations of vitelline substance, which simulate nuclei; but the origin and meaning of these are left in doubt. Other appearances, as of systems of strix, are also mentioned as occurring in larger ovarian ova. With regard to the membranes of the ovum the author differs from Waldeyer and agrees with Balfour in regarding the zona radiata as a product of the protoplasm of the ovum, and not as derived from the cells of the follicular epithelium.

The ovarian ovum of the rabbit is next described, and is found to agree in most essential particulars with that of the bird. The zona pellucida is porous, and allows granules of foodmaterial to pass from the epithelium cells of the Graafian follicle directly into the vitellus. But it is chiefly in this epithelium that the interest centres, for the inner layer of cells of the follicular epithelium appears to be formed in the peripheral layer of the vitellus of the ovum itself, making their appearance first of all as mere nuclei (derived in all probability from the nucleus of the ovum), around which part of the protoplasm or vitellus of the ovum becomes segmented off. This description is compared with that which Kuppfer gives of the formation of an inner layer of follicular epithelium from nuclei which make their appearance in the periphery of the vitellus of the ovum of Ascidia canina, and with the observations of Kleinenberg upon the formation of a layer of cells from the periphery of the ovum of Hydra.

Finally the gland-like nature of the ovarian tubes in the bitch's ovary is insisted upon in agreement with Pfluger and Waldeyer, and in opposition to the view taken by Foulis.

January 13.- "On the Forty-eight Co-ordinates of a Cubic Curve in Space," by William Spottiswoode, President R.S.

In a note published in the Report of the British Association for 1878 (Dublin), and in a fuller paper in the Transactions of the London Mathematical Society, 1879 (vol. x. No. 152), I have given the forms of the eighteen, or the twenty-one (as there explained), co-ordinates of a conic in space, corresponding, so far as correspondence subsists, with the six co-ordinates of a straight line in space. And in the same papers I have esta. blished the identical relations between these co-ordinates, whereby the number of independent quantities is reduced to eight, as it should be. In both cases, viz., the straight line and the cubic, the co-ordinates are to be obtained by eliminating the variables in turn from the two equations representing the line or the conic, and are, in fact, the coefficients of the equations resulting from the eliminations.

In the present paper I have followed the same procedure for the case of a cubic curve in space. Such a curve may, as is well known, be regarded as the intersection of two quadric surfaces having a generating line in common; and the result of the elimination of any one of the variables from two quadric equa. tions satisfying this condition is of the third degree. The number of coefficients so arising is $4 \times 10=40$; but I have found that these forty quantities may very conveniently be replaced by forty-eight others, which are henceforward considered as the co-ordinates of the cubic curve in space.

The number of identical relations established in the present paper is thirty-four. But it will be observed that the equations are lineo-linear in each of two groups, say the U-co-ordinates and the $U^{\prime}$-co-ordinates; and as we are concerned with the ratios only of the coefficients, and not with their absolute values, we are, in fact, concerned only with the ratios of the U-co-ordinates inter se, and the U'-co-ordinates inter se, and not with their absolute values. Hence the number of independent co-ordinates will be reduced to $48-34-2=12$, as it should be.

Mathematical Society, January 13.-S. Roberts, F.R.S., president, in the chair.-Miss C. A. Scott and Messrs. J. Parker Smith, O. H. Mitchell, Fellow of Johns Hopkins University, and T. Craig, U.S. Coast Survey Office, Washington, were elected members. Dr. Hirst, in drawing attention to the loss the Society had sustained by the death of M. Chasles, gave a rapid sketch of that distinguished geometer's career and work ; in lightly touching upon his private life he mentioned how gratified M. Chasles had been by the fact that he was not only the first Foreign Member of the Society, but for a long time the only one. The following communications were made :-On an apparently paradoxical relation of the circle, parabola, and hyperbola, by A. J. Ellis, F.R.S.-A proof of the differential equation which is satisfied by the hypergeometric series, by the Rev. T. R. Terry.-On the periodicity of hyperelliptic integrals of the first class, by W. R. W. Roberts.-On the tangents drawn from a point to a nodal cubic, by R. A. Roberts.-Sur une propriété du paramètre de la transformée canonique des formes cubiques ternaires, by Signor Brioschi (Milan). - Note on a kinematical theorem connected with the rectilinear courses of two vessels sailing uniformly, by C. W. Merrifield, F.R.S.-A partition-problem connecting the angles of a triangle with the angles of the successive pedal triangles, by J. W. L. Glaisher, F.R.S.

\section{PARIS}

Academy of Sciences, January ro.-M. Wurtz in the chair. - The following papers were read:-On the conditions 
relative to the theoretic expression of the velocity of light, by M. Cornu. - Crystalline substances produced from old medals immersed in the thermal waters of Baracci, commune of Olmeto (Corsica), by M. Daubrée. Some of these brenze medals had merely a dark patina resulting from superficial sulphuration. A few others had a thick crystalline crust, the substance being apparently a double sulphide of copper and tin (of which the nearest natural analogue would be stannine). The water, contair.ing only 0.3 gr. of mineral matters per litre, has chloride of sodium, sulphate of soda, and silica in predominance.--On the star-fishes dredged in the deep regions of the Gulf of Mexico and the Carribean Sea by the American ship the Blake, by M. Perrier. The new collections raise the number of species from twenty-seven to seventy. A pretty large number are new generic types.-On a class of linear differential equations, the coefficients of which are algebraic functions of the independent variable, by M. Appell.-On the circulatory apraratus of isopod crustaceans, by M. Delage.-Phylloxera in California, by M. de Lavignon. The old vine-growers say they have always known it, and they do not regard it as introduced with plants from Bordelais. Its effects are the same in kind as in France, but its progress is very slow by reason of absence (apparently) of the winged insect, quality of the soil (rich and deep), and the existence of an acarian parasite (Tyroglyphus longior).The Inspector-General of Navigation reported on the variations of the Seine at Paris in 1880. The highest water was on January 4, the lowe t on February 3 and 4.-On a process of astronomical observation for use of voyagers, \&c. (continued), by M. Ronget.--On the transformation of reciprocal directions, by $M$. Lavuerre.-On the size and variations of Purkinje's images, by M. Croullehois. It is proved that the mechanism of the adaptation consists in a simultaneous modification of the curvature of the two faces of the crystalline lens. Thermo-regulator for high temperatures, by M. D'Arsonval. This is ap licable up to $1200^{\circ}$ at least. A regulator like that before described has its space under the membrane connected by means of a capillary tube with a short hollow stem which can be op:ned or closed with a screw and is connected by two tubes with a mercury manometer, and an air.reservoir (of glass or porcelain) to be put in the medium that is to be kept con-tant. For temperatures over $300^{\circ}$ he opens the stem when I atm. has been reached, and so lets the manometer come back t.) zero before closing again. A new method of reading must then, of course, be adopted.-Investigation of gnseous compounds and study of some of their properties with the spectroscope, by MM. Hautefenille and Chappuis. With the spectroscope one can follow the isomeric change of ozone into oxysen, and prove that its destruction does not give hyponitric acid. Electrification of a dry mixture of nitrosen and oxygen, containing at least one-seventh of the former, gives a substance not before observed, and having a remarkableabsorption-spectrum. It is thought to be pernitric acid, analog us to M. Berthelot's persulphuric acid.-On bromides and jodides of phos phorus, by M. Ogier. -Rapid stoppage of the rhythmic contractions of the cardiac ventricles through acclusion of the coronary arteries, by MM. Sée, Bochefontaine, and Ronssy:-On the application of anatomical exausination of the blood to diagnosis of disease, by M. Hayem. He gives two methods: examination of pure blood, in a thin layer, of constant thickness; and examination of blood diluted with a special reagent. The phenomena in certain diseases are described.-On the quantity of light necessary to perceive the colour of objects of different surfaces, by M. Charpentier. For retinal surfaces $1 \frac{88}{1000}$ to $\frac{440}{1000} \mathrm{~mm}$. square the illumination necessary to make or perceive colour (o ce the luminous sensibility is obtained) was the same for each colour tried. It may, then, be said that for red, yellow, green, and blue the chromatic sensibility is independent of the retinal surface excited. Influence exerted by environment on the farm, structure, and mode of reproduction of Isoetes lacustris, by M. Mer.-On the conservation ff yrain in closed reservoirs, by M. Muntz. With renewal of air he found about ten times more $\mathrm{CO}_{2}$ produced than in a closed vessel. The volume of $\mathrm{CO}_{2}$ found in contact with air is alway, less than that of $\mathrm{O}$ absorbed. The $\mathrm{O}$ is chiefly fixed by fatty inatters. Too dry grain, not giving much of an asphyxiating at mosphere, is liable to the rawages of insects. The proportion of $\mathrm{CO}_{2}$ increases rapidly with the degree of moisttre. As the temperature is raised there is physiological combustion up to a point (about $50^{\circ}$ ), thereafter chemical. Anæsthetic;, like. sulphide of carbon, diminish, without stopping, the formation of $\mathrm{CO}$-On a simple means of bringing to life new barn infrmts in a state of apparent death, by M. Gozard. He describes a successful application of M. Le Bon's suggestion for young asphyxiated animals, immersing in a water-bath heated $45^{\circ}$ to $50^{\circ}$.- M. Boutigny invited attention to the fact that boiling water projected on an incandescent surface instantly falls in temperature to $97^{\circ}$. He attributes this cooling to work done in production of the spheroidal state.

\section{BERLIN}

Geographical Society, January 8.-Dr. Nachtigal, president.-The President gave a sketch of the work of the Society's explorers for the past year. It was hoped that Dr. Lenz would have been present at the meeting, but he had been unable to leave St. Louis in Senegal, as yellow fever prevailed there. After a long interval letters had been received from Dr. Buchner, dated February, May, and July last. He had been for six months in Mussumba in Muatà Janvo's kingdom, carrying on topographical, photographic, and natural history work. After sending most of his papers and collections to Angola he proceeded northwards, writing on July I from Muene Chikambo. Dr. Nachtigal then referred to the East African Expedition, which, along with Capt. Ramzeckers, has arrived at Tabora, and Dr. Rohlfs party, who on December 12 were at Massowah. Herr. Buchter exhibited a large number of photographs and drawings from the Upper Nile.

\section{VIENNA}

Imperial Academy of S Sciences, January 7.-On the quantitative relations of electric expansion in glass and caoutchouc, by G. Korteweg and V. A. Julius.-Preliminary note on decomposition of water, by $C$. Baudet.-Researches on fats, by D. G. Goldschmiedt and M. v. Schmidt.-On an uncrystallisable acid obtained from albumen by oxidation with permanganate of potash, by E. v. Bruecke.

\section{CONTENTS}

PAGE

North Ambrican Pinnipeds . . . . . . . . . . . $26 \mathrm{I}$ Catalogue of NewCastle Libraries . . . . . . . . . . 262 Uur BOOK SHRLF :-

Botanische Jahrbücher für Systematik Pfianzengeschichte und Pflanzengeographie" ". . . . . . .

Day's "Fishes of Great Britain and Ireland" " : : . : . : . : 263

Kent's "Manual of the Infusoria" Palliser's "Complete Course of Problems in Practical Plane "Bericht über die Thätigkeit der Botanischen Section der Schlesischen Gesellschaft im Jahre $1877 "$. . . . . . . . . LETTHRS TO THE EDITOR :-

Dr. Carnelley's Hot Ice.-Dr. Orrver J. Longe * * * . 264 On the Spectrum of Carbon.-Prof. G D. LiveING, F.R.S.; Dr.

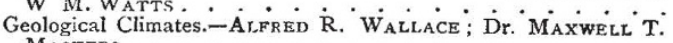
MASTERS.

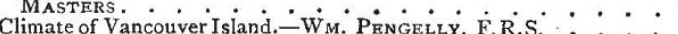
Dimorphic Leaves of Conifers.-Dr. MAXwELL T. MASTERS $\cdot{ }^{267}$ Dust and Fogs.-Hon. R. RUSৎELL

A "Natural" Experiment in Polarised Light-Chas. $\dot{T}$. Whit:

MELL... . . . . . . . . . . . . ${ }_{2} 68$ Statics and Dynamics of Skating. By Charles Alex. Steven-

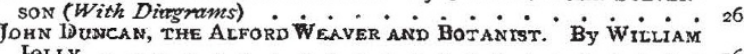

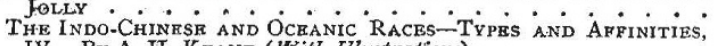
IV. By A. H. KEANE (With Illustrations) . . . . . . . . 27 The PhOTOPHONe. By Lord RaYleigh, F.R.S. : : : : : : : 27 Notes . . . . . . . . . . . . 27 Ur Astronomical Column :-

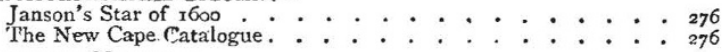
Brologtcal Notes:-

Archæopteryx macrura $. . \cdot \cdot \cdot, \cdot . \cdot, \cdot, \cdot, 276$

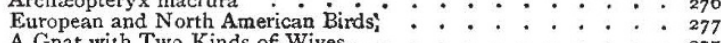

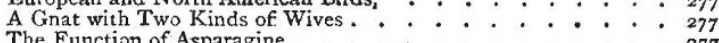

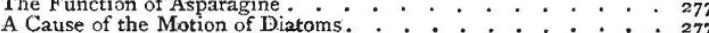

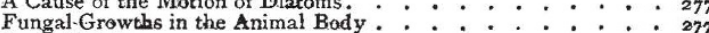

Brain-Weight . . . . * . . . : . . . . . : $: 277$ Physical Noths

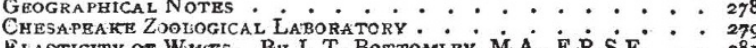
Elastictry of W. Wes. By J. T. BotTomLey, M.A., F.R.S.E. : : 289

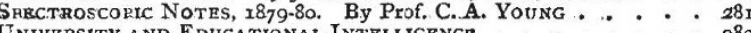
UNIVERSTTY AND EDUCATIONAL INTRLLIGENCE . . . . . . . . 282

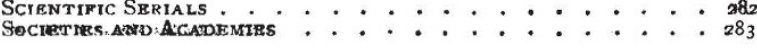

